\title{
Association of diet-related knowledge, attitude, behaviors and self-rated health among Chinese adults: a population-based study
}

\section{Ying Yang}

Wuhan University https://orcid.org/0000-0001-9252-5071

Di He

Tongji Hospital of Tongji Medical College of Huazhong University of Science and Technology

Liuyi Wei

Wuhan University

Shizhen Wang

Wuhan University

Lei Chen

Wuhan University

Mi Luo

Wuhan University

Zongfu Mao ( $\boldsymbol{\nabla}$ zfmao@whu.edu.cn )

https://orcid.org/0000-0001-9477-4725

\section{Research article}

Keywords: diet, knowledge, attitude, behavior, self-rated health, China

Posted Date: April 28th, 2020

DOI: https://doi.org/10.21203/rs.2.18289/v2

License: (9) This work is licensed under a Creative Commons Attribution 4.0 International License.

Read Full License

Version of Record: A version of this preprint was published at BMC Public Health on May 19th, 2020. See the published version at https://doi.org/10.1186/s12889-020-08896-y. 


\section{Abstract}

Background: Diet and nutrition play an important role in one's health status. The objectives of this study were to (a) determine knowledge, attitude, and behaviors (KABs) related to diet among a sample of Chinese adults, and (b) assess the association between diet-related KABs and self-rated health.

Methods: We analyzed the 2015 CHNS data. Individuals aged 18 years and older were included as study subjects $(n=12,814)$. Five variables were selected to assess diet-related knowledge, attitude, and behaviors. Comparison of diet-related KABs in urban and rural was conducted using chi-square test. Ordinal logistic regression was conducted to quantify the association between diet-related KABs and selfrated health.

Results: The awareness proportion for Chinese diet pagoda/DGCR was $27.1 \%$, and only $34.3 \%$ of the subjects were assessed as having adequate dietary knowledge literacy. $24.3 \%$ reported positive attitude towards healthy diet. $27.6 \%$ and $65.9 \%$ reported the behavior of actively looking for nutrition knowledge and eating fruit $\&$ vegetables, respectively. Chi-square test indicated that rural residents experienced significant poorer diet-related knowledge, attitude, and behaviors than urban (all $p$-values $<0.01$ ). Adjusted ORs with $95 \% \mathrm{Cl}$ revealed significant association between diet-related KABs and self-rated health.

Conclusions: Chinese adults experienced poor diet-related knowledge, attitude, and behaviors, while rural residents were significantly worse than urban. Better diet-related knowledge, attitude, and behaviors was associated with higher self-rated health.

\section{Background}

According to the Global Burden of Disease Study 2017, 11 million deaths (22\% of all deaths among adults) and 255 million Disability Adjusted Life Years (DALYs) were attributable to dietary risk factors [1]. In China, we are confronting with the plight: coexistence of under- and over-nutrition, as well as high incidence of nutrition-related diseases [2]. Chinese residents' daily salt and edible oil intake, together with fat ratio is all higher than the recommended standards (WHO and Dietary Guidelines for Chinese Residents (DGCR)) in 2012 [2]. The overweight and obesity rates in adults maintain an upward trend, while $6.0 \%$ and $9.0 \%$ of whom still have problems of malnutrition and weight loss. To promote the solution of nutrition-related problems, the Chinese government announced the implementation of “Healthy China Action (2019-2030)" in July 2019, "Appropriate Diet" was involved as one of its fifteen major actions [3].

Knowledge, Attitude/Belief, and Behavior/Practice (KAB) is originally proposed to emphasize the vital role of knowledge, attitude, and behavior in promoting individuals' health management [4]. According to the theory, individuals' health behavior is composed of three consecutive processes: acquire knowledge, generate beliefs, and form behaviors. KAB evaluation is considered the first step of health behavior education, which can grasp the individual's understanding, health beliefs, and actions taken regards a 
specific health issue, and then provide scientific basis for the development of intervention plan. Adequate knowledge of health-related behavior has been reported to influence the patient's attitude and practice in health management [5]. Specifically, assessing diet-related knowledge, attitude, and behaviors has been reported to be vitally important in achieving dietary health promotion at the population level [6-8], thus should be a necessary prerequisite for dietary intervention in China.

Previous studies have shown that diet-related behavior is a key factor influencing individuals' health, for example, associating with mortality and morbidity of non-communicable diseases [1], risk of cardiovascular disease [9, 10], metabolic syndrome [11-13], cancer [9, 14], and all-cause mortality [9]. Knowledge and attitude indirectly affect health status by promoting behavioral change $[15,16]$. However, no existing study has systematically described the association of Chinese residents' dietary behavior on individuals' health, based on the KABs theory perspective. For these consideration, we conducted this study to (a) determine knowledge, attitude, and behaviors related to diet among a sample of Chinese adult residents, and (b) assess the association between diet-related KABs and self-rated health.

\section{Methods}

\section{Date source}

The China Health and Nutrition Survey (CHNS) is a longitudinal survey and open cohort conducted from 1989 to the currently available 2015 wave, with multistage and random cluster procedures. This comprehensive dataset aims to study the influences of nutrition, health, and family planning policies established by both national and local government agencies in China. Furthermore, the CHNS investigates the impact of social and economic transitions in Chinese society on residents' overall health and nutrition status. In the 2015 CHNS wave, a total of 15,291 individuals from nine provinces (Liaoning, Heilongjiang, Jiangsu, Shandong, Henan, Hubei, Hunan, Guangxi, and Guizhou) and three municipalities (Beijing, Chongqing, and Shanghai) were surveyed.

In this study, we used the data of adult population (aged 18 and over) in the 2015 CHNS wave ( $n=$ 12,872). After excluding those with missing socio-demographic, diet related variables, and self-rated health information, a total of 12,814 subjects were involved in the final analysis.

We used de-identified and publicly-available datasets from the official CHNS website (https://www.cpc.unc.edu/projects/china). Hence, approvals from Institutional Review Boards were not required at authors' institutions.

\section{Variables}

\section{Diet-related knowledge}

We applied two variables to assess diet-related knowledge: the awareness of Chinese diet pagoda or Dietary Guidelines for Chinese Residents (DGCR) and adequate dietary knowledge literacy. The awareness of diet pyramid/ DGCR was identified by a question "Do you know about the Chinese Pagoda 
or the Dietary Guidelines for Chinese Residents (yes/no)?" Dietary knowledge literacy was computed from 17 dietary questions. Referring to the statistical analysis of Chinese residents health literacy monitoring [17] and previous relevant article [18], individuals with the actual dietary knowledge score $\geq 80 \%$ were defined as having adequate dietary knowledge literacy (i.e. the total score of 17 dietary questions $\geq 14$ ).

17 questions which originally coded as "strongly disagree", "disagree", "neutral", "agree", and "strongly agree" in the 2015 CHNS questionnaire was transferred into dichotomous variables. For seven negative items (Q2, Q4, Q6, Q12, Q14, Q15, Q16), the response of "strongly disagree" or "disagree" was scored 1 point, otherwise 0 . For the other ten positive items, the response of "strongly agree" or "agree" was scored 1 point, otherwise 0 . Cronbach's alpha for the 17 dietary questions was 0.86 in this study.

\section{Diet-related attitude}

The attitude towards the importance of "eating a healthy diet" were selected as diet-related attitude measurement. The answers were dichotomized to positive attitude ("very important" or "the most important") and non-positive attitude ("not important at all", "not very important", or "neutral").

\section{Diet-related behaviors}

Two categorical variables were applied to assess diet-related behaviors: actively looking for nutrition knowledge, and prefer eating fruits \& vegetables. The behavior of looking for nutrition knowledge was measured by a question "Do you proactively look for nutrition knowledge (yes/no)?" The response of "yes" was referred to as positive behavior. The question regarding behavior of eating fruits \& vegetables were dichotomized to positive behavior ("like" and "like very much") and non-positive behavior ("dislike very much", "dislike", “neutral”).

\section{Self-rated health}

Self-rated health was assessed by the question "How do you rate the quality of your life at present?" The original coding included "very good", "good", "fair", "bad", and "very bad". The response of "very good" and "good" was recognized as good health, "fair" as moderate health, "bad" and "very bad" as poor health.

\section{Covariates}

Covariates including age, gender, marital status, education level, work status, and place of residence were collected. Age was classified into three categories (18-44, 45-59, and $\geq 60)$. Marital status was dichotomized into married and others (never married, divorced, widowed, separated, etc.). Education level was classified into four categories (elementary school and below, middle school, high school, and college and above). Work status was classified into two categories (yes and no). Place of residence was dichotomized into urban and rural.

\section{Statistical analysis}


Data analysis was performed by using IBM SPSS Statistics Version 22.0 (SPSS, Inc., Chicago, IL). Descriptive statistics including means and standard deviation (SD), frequency and percentages were calculated. Comparison of diet-related knowledge, attitude, and behaviors among urban and rural residents were conducted using chi-square test. Ordinal logistic regression was conducted yielding adjusted odds ratios (ORs) to identify the association between diet-related KABs and self-rated health. In all analyses, a $p$-value of $\leq 0.05$ was considered significant.

\section{Results}

\section{General information}

A total of 12,814 adult individuals were involved in this study, composed of $39.5 \%(n=5,061)$ in urban and $60.5 \%(n=7,753)$ in rural areas. The participants' average age was 52.6 years old $(S D=15.3)$, of which $30.3 \%(n=3,887), 34.1 \%(n=4,375)$, and $35.5 \%(n=4,552)$ were young, middle, and older adults, respectively. Of these participants, $46.9 \%(n=6,016)$ were male, $86.1 \%(n=11,038)$ were married, $32.2 \%$ $(n=4,132)$ received an education level below middle school, $46.0 \%(n=5,891)$ were currently employed. $8.5 \%(n=1,089), 40.3 \%(n=5,159)$, and $51.2 \%(n=6,566)$ of the participants self-reported poor, moderate, and good health status, respectively. The differences of self-rated health in demographic characteristics were statistically significant (all $p$-values $<0.05$ ). Table 1 lists the detailed characteristics of the study sample by self-rated health.

\section{Diet-related KABs}

In regards to diet-related knowledge, only $27.1 \%$ of the participants knew Chinese diet pagoda/DGCR, and $34.3 \%$ were assessed as having adequate dietary knowledge literacy. In attitude, $24.3 \%$ of the participants hold positive attitude towards healthy diet. In terms of behaviors, $27.6 \%$ of the participants reported the behavior of actively looking for nutrition knowledge, and the majority (65.9\%) reported preference to fruits $\&$ vegetables. The comparative analysis indicated that participants in urban areas had significantly better knowledge, attitude, and behaviors related to diet than that in rural (all $p$-values $<0.01$ ). Most prominently, the awareness proportion of Chinese diet pagoda/DGCR (38.6\%) and the proportion of actively looking for nutrition knowledge (40.5\%) in urban was almost the double of which in rural (19.5\% and $19.2 \%)$. As shown in Table 2.

Besides, Table 3 demonstrated the awareness proportion of 17 dietary knowledge-based questions and the differences in urban and rural. The awareness proportion of the 17 questions ranged from $28.1 \%$ (Q14, refined grains contain more vitamins and minerals than unrefined grains) to $83.2 \%$ (Q9, consuming beans and bean products is good for one's health), with an average of $64.9 \%$. And only $1.1 \%(n=143)$ of the participants were aware of all the 17 items. Urban participants reported significantly higher awareness proportion of dietary knowledge (except for Q9 and Q14) than rural ( $p$-value $<0.01$ ).

\section{Association between diet-related KABs and self-rated health}


Adjusted ORs with 95\% Cl were computed to clarify the association between diet-related KABs and individuals' self-rated health (Table 4). Participants aware of Chinese diet pagoda/DGCR (OR = 1.11, 95\% $\mathrm{Cl}=1.08-1.15)$, having diet knowledge literacy $(\mathrm{OR}=1.12,95 \% \mathrm{Cl}=1.10-1.15)$, holding positive attitude towards the importance of healthy diet $(\mathrm{OR}=1.14,95 \% \mathrm{Cl}=1.09-1.19)$, actively looking for nutrition knowledge $(\mathrm{OR}=1.11,95 \% \mathrm{Cl}=1.08-1.15)$, and preferring fruits \& vegetables $(\mathrm{OR}=1.09,95 \% \mathrm{Cl}=1.07$ 1.12) were detected with significant better self-rated health.

\section{Discussion}

With the improvement of people's living standards, the dietary patterns of Chinese residents have gradually changed - the unhealthy dietary structure such as high-energy, high-fat, and high-sugar intake has been increasingly prominent $[19,20]$. Advocating a balanced diet and strengthening diet-related health education have become a noteworthy topic in China [3]. This study showed that Chinese adults experienced poor diet-related knowledge, attitude, and behaviors, while rural residents were notably worse than urban. We also found that diet-related knowledge, attitude, and behaviors all associated with individuals' self-rated health.

This study demonstrated that the awareness proportion of Chinese diet pagoda/DGCR was $27.1 \%$, and the proportion of having adequate dietary knowledge literacy was 34.3\%, which was consistent with Li et al.'s report (27.0\% and 36.0\%) [18]. Notably, compared with historical data [21], the awareness proportion of Chinese diet pagoda/DGCR presented a clear upward trend (2004, 7.8\%; 2006, 11.9\%; 2009, 14.6\%; and $2011,24.4 \%)$, but still at a low level. Besides, only about one-third of the Chinese adult residents were equipped with basic dietary knowledge, and the awareness proportions of several dietary knowledge were extremely low. For example, the correct proportions for Q14 (Refined grains contain more vitamins and minerals than unrefined grains), Q5 (Choosing a diet with a lot of staple foods is not good for one's health), and Q16 (Vegetables contain more starch than staple foods) were only $28.1 \%, 41.2 \%$ and $44.5 \%$, respectively. It can be seen that certain diet-related knowledge of Chinese adult residents is still poor and needs to be strengthened. Therefore, the residents are not only supposed to acquire basic nutrient information, but also should be recommended appropriate diet patterns according to their nutritional status by general practitioner, nutritionist and related professionals [22].

As the important dimension of the health belief model, individuals' health-related attitude greatly affects the formation of health-related behaviors [23]. Only about one quarter of participants reported positive attitude towards healthy eating (24.3\%). Despite the fact that high diet quality is closely associated with lower incidence of hypertension and other diseases [24, 25], Chinese residents have not generally recognized the importance of healthy lifestyle yet.

In terms of diet-related behaviors, we obtained identical results with Li et al. [18]. Although the minority of the participants $(27.6 \%)$ reported actively looking for nutrition knowledge, most (65.9\%) adult residents preferred fruits and vegetables in their daily diet. However, according to Li et al. [26] and Ouyang et al. [27], the actual intake of fruits and vegetables of Chinese residents have not yet met the international 
recommendation. Some even reported a decrease in the consumption of vegetables [28]. Because people tend to eat ultra-processed foods that are known to decreases the overall diet quality in recent years [29, 30]. Thus, future measures are expected to encourage intake of fruits and vegetables as well as improve the traditional Chinese cooking methods to prevent nutrient loss. In general, diet-related knowledge, attitude, and behaviors of Chinese adult residents are not satisfactory, and it is necessary to carry out targeted health education to guide and improve.

Comparative analyses suggested that rural residents experienced significant worse diet-related knowledge, attitude and behaviors. Especially for the awareness proportion of Chinese diet pagoda/DGCR (knowledge) and the proportion of actively looking for nutrition knowledge (behavior), rural areas were just about $1 / 2$ of urban. The results were consistent with previous findings that also exhibited an obvious urban-rural dual structure of diet-related KABs in China [31,32]. There was thus a need to address this gap in research and to develop interventions that targeted rural residents in particular. While urbanization in China gave rural residents more opportunity to all aspects of the information, not enough health resources are available. The government still should strengthen the effort to promote diet-related health education. For example, both free clinic activity and bulletin boards are valid health promotion medium for rural residents.

The results of regression analysis showed that positive diet-related knowledge, attitude, and behaviors were the protective factors for individuals' self-rated health. A study across five European countries addressed consistent findings that [16], enhancing nutrition-related knowledge and attitude could strongly and positively influence the health status and quality of life among the older population. Aune et al. [9] stated that fruit and vegetable intakes closely associated with individuals' health, and could effectively reduce the risk of cardiovascular disease, total cancer, and all-cause mortality. These findings are primer for policy makers to implement diet-related health education programs.

With the construction of "Health China", the Chinese government implemented "Appropriate Diet" action as part of the "Healthy China Action (2019-2030)" [3]. However, improving diet-related KABs in China is not an easy task. It requires not only an understanding of the demand discrepancy between urban and rural adults, but also an insight into the factors preventing adults from a healthy diet. As the KABs theory demonstrates, our study reinforced the importance of creating good conditions for diet-related health resources, especially in rural areas. Holistic policy intervention is warranted to target Chinese adults' overall diet-related knowledge and behavior rather than relative motivation alone.

Several potential limitations should be mentioned regarding the present study. Firstly, limited by the data structure and content of the CHNS database, we only selected two variables (looking for nutrition knowledge, eating fruit and vegetables) to evaluate diet-related behavior, which may not fully reflect the dietary behavior of Chinese adult residents. Secondly, all measures in the study are self-reported, and thus are subject to various measurement errors. For example, the application of self-rated health may result an assess gap with individuals' actual health status. Due to data limitation, this study is not able to address more objective and comprehensive health status indicators (i.e. illness, blood pressure, blood glucose). 
Thirdly, considering the data timeliness, the 2015 CHNS data may not fully reflect China's current situation. Despite these limitations, the present study systematically described the dietary condition of Chinese adult residents based on large sample data. And this is the first to explore the impact of dietrelated knowledge, attitude, and behaviors on individuals' health among the Chinese adult population, which might be a valuable reference for the implementation of current "Appropriate Diet" actions and further relevant research.

\section{Conclusions}

Chinese adults experienced poor diet-related knowledge, attitude, and behaviors, while rural residents were significantly worse than urban. Great diet-related knowledge, attitude, and behaviors significantly associated with the improving of individuals' self-rated health. The "Appropriate Diet" action implemented in China is in line with the general scientific path of promoting population health through behavioral intervention. It is necessary to develop targeted interventions towards three dietary dimensions (knowledge, attitude, and behavior). Moreover, the focus of policy on rural areas to address the urbanrural gap in dietary health might make great sense.

\section{Abbreviations}

CHNS: China Health and Nutrition Survey; Cl: Confidence interval; DALYs: Disability Adjusted Life Years; DGCR: Dietary Guidelines for Chinese Residents; KABs: Knowledge, attitude, and behaviors; OR: Odds ratio; SD: Standard deviation

\section{Declarations}

\section{Ethics approval and consent to participate}

We used publicly-available datasets from the official CHNS website (https://www.cpc.unc.edu/projects/china). Hence, the need for ethics approval was waived by the Institutional Review Board of Wuhan University. The CHNS provides respondents guarantees of their privacy and confidentially. All participants provided written informed consent. Details about the study design are available elsewhere [33].

\section{Consent for publication}

Not applicable.

\section{Availability of data and materials}

The datasets generated and/or analysed during the current study are available from the official CHNS website (https://www.cpc.unc.edu/projects/china). 
The authors declare that they have no competing interests.

\section{Funding}

This work was supported by the Global Health Institute, Wuhan University, China. The role of funding body included designing the study, analysis and interpretation of data, and writing the manuscript.

\section{Authors' contributions}

YY and DH designed the study. LW, SW, LC, ML analyzed and interpreted the data. YY and DH drafted the manuscript. ZM supervised the study and critically revised the manuscript for important intellectual content and final approval of the version to be published. All authors have read and approved the final manuscript.

\section{Acknowledgements}

Not applicable.

\section{Authors' information}

${ }^{1}$ School of Health Sciences, Wuhan University, 115\# Donghu Road, Wuhan 430071, China

${ }^{2}$ Global Health Institute, Wuhan University, 115\# Donghu Road, Wuhan 430071, China

${ }^{3}$ Department of Nursing, Tongji Hospital, Tongji Medical College, Huazhong University of Science \& Technology, 1095\# Jiefang Avenue, Wuhan 430030, China

\section{References}

1. Afshin A, Sur PJ, Fay KA, Cornaby L, Ferrara G, Salama JS, Mullany EC, Abate KH, Abbafati C, Abebe $Z$ et al. Health effects of dietary risks in 195 countries, 1990-2017: a systematic analysis for the Global Burden of Disease Study 2017. The Lancet 2019, 393(10184):1958-1972. http://dx.doi.org/10.1016/S0140-6736(19)30041-8

2. Department of Disease Prevention and Control, National Health and Family Planning Commission. Report on Chinese Residents' Chronic Diseases and Nutrition, 2015. Beijing: People's Medical Publishing House; 2015.

3. National Health Commission of the People's Republic of China. Healthy China Initiative (2019-2030). 2016; [cited November 2019]. Available from: http://www.nhc.gov.cn/guihuaxxs/s3585u/201907/e9275fb95d5b4295be8308415d4cd1b2.shtml

4. Zhu J. Health Behavior and Health Education. Shanghai: Fudan University Press; 2013.

5. Maruf FA, Ojukwu CC, Akindele MO. Perception, Knowledge, and Attitude toward Physical Activity Behaviour: Implications for Participation among Individuals with Essential Hypertension. High Blood 
Pressure \& Cardiovascular Prevention 2018, 25(1):53-60. http://dx.doi.org/10.1007/s40292-0170235-y

6. Spronk I, Kullen C, Burdon C, O'Connor H. Relationship between nutrition knowledge and dietary intake. Br J Nutr 2014, 111(10):1713-1726. http://dx.doi.org/10.1017/S0007114514000087

7. Axelson ML, Federline TL, Brinberg D. A meta-analysis of food- and nutrition-related research. Journal of Nutrition Education 1985, 17(2):51-54. http://dx.doi.org/10.1016/S0022-3182(85)80175-8

8. Macías YF, Glasauer P. Guidelines for assessing nutrition-related knowledge, attitudes and practices. Rome: Food and Agriculture Organization of the United Nations; 2014.

9. Aune D, Giovannucci E, Boffetta P, Fadnes LT, Keum N, Norat T, Greenwood DC, Riboli E, Vatten LJ, Tonstad S. Fruit and vegetable intake and the risk of cardiovascular disease, total cancer and allcause mortality - a systematic review and dose-response meta-analysis of prospective studies. INT J EPIDEMIOL 2017, 46(3):1029-1056. http://dx.doi.org/10.1093/ije/dyw319

10. Ruan Y, Huang Y, Zhang Q, Qin S, Du X, Sun Y. Association between dietary patterns and hypertension among Han and multi-ethnic population in southwest China. BMC PUBLIC HEALTH 2018, 18(1):11061108. http://dx.doi.org/10.1186/s12889-018-6003-7

11. Mirmiran P, Ziadlou M, Karimi S, Hosseini-Esfahani F, Azizi F. The association of dietary patterns and adherence to WHO healthy diet with metabolic syndrome in children and adolescents: Tehran lipid and glucose study. BMC PUBLIC HEALTH 2019, 19(1):1457. http://dx.doi.org/10.1186/s12889-0197779-9

12. Mumme KD, von Hurst PR, Conlon CA, Jones B, Haskell-Ramsay CF, Stonehouse W, Heath AM, Coad J, Beck KL. Study protocol: associations between dietary patterns, cognitive function and metabolic syndrome in older adults - a cross-sectional study. BMC PUBLIC HEALTH 2019, 19(1):535. http://dx.doi.org/10.1186/s12889-019-6900-4

13. Mohammadi S, Jalaludin MY, Su TT, Dahlui M, Mohamed M, Majid HA. Dietary and physical activity patterns related to cardio-metabolic health among Malaysian adolescents: a systematic review. BMC PUBLIC HEALTH 2019, 19(1):251. http://dx.doi.org/10.1186/s12889-019-6557-z

14. Chang YJ, Hou YC, Chen LJ, Wu JH, Wu CC, Chang YJ, Chung KP. Is vegetarian diet associated with a lower risk of breast cancer in Taiwanese women? BMC PUBLIC HEALTH 2017, 17(1):800. http://dx.doi.org/10.1186/s12889-017-4819-1

15. Pickard AS, Jalundhwala YJ, Bewsher H, Sharp LK, Walton SM, Schumock GT, Caskey RN. Lifestylerelated attitudes: do they explain self-rated health and life-satisfaction? QUAL LIFE RES 2018, 27(5):1227-1235. http://dx.doi.org/10.1007/s11136-017-1774-3

16. Jeruszka-Bielak M, Kollajtis-Dolowy A, Santoro A, Ostan R, Berendsen AAM, Jennings A, Meunier N, Marseglia A, Caumon E, Gillings R et al. Are Nutrition-Related Knowledge and Attitudes Reflected in Lifestyle and Health Among Elderly People? A Study Across Five European Countries. FRONT PHYSIOL 2018, 9. http://dx.doi.org/10.3389/fphys.2018.00994

17. Nie X, Li Y, Li L. Statistic analysis of 2012 Chinese residents health literacy monitoring. Chinese Journal of Health Education 2014, 30(02):178-181. http://dx.doi.org/10.16168/j.cnki.issn.1002- 
9982.2014.02.021

18. Li Y, Zhang F, Wang T. Status quo of dietary knowledge and attitudes and influencing factors of dietary health literacy among adult residents in China, 2015. Chin J Public Health 2019:1-4. http://dx.doi.org/10.11847/zgggws1121422

19. Ju L, Yu D, Fang H, Guo Q, Xu X, Zhao L. Dietary patterns among Chinese residents, 2010-2012. Chin J Public Health 2018, 34(10):1373-1376. http://dx.doi.org/10.11847/zgggws1116952

20. Liu M, Yan L, Liu M, Liu Z, Ma M, Yang Y. The Dietary Status of Residents in Sichuan Province. J Prev Med Inf 2018, 34(03):357-361

21. Huang $F$, Wang $H$, Zhang J, Zhai F, Zhang $B$. The trends in awareness rate of the dietary guidelines for Chinese residents and the effect on dietary pattern. Acta Nutrimenta Sinica 2015, 37(04):325-329. http://dx.doi.org/10.13325/j.cnki.acta.nutr.sin.2015.04.007

22. Baldwin C, Weekes CE: Dietary advice with or without oral nutritional supplements for disease-related malnutrition in adults. The Cochrane database of systematic reviews 2011(9):D2008. http://dx.doi.org/10.1002/14651858.CD002008.pub4.

23. Le J, Dallongeville J, Wagner A, Arveiler D, Haas B, Cottel D, Simon C, Dauchet L: Attitudes toward healthy eating: a mediator of the educational level-diet relationship. EUR J CLIN NUTR 2013, 67(8):808-814. http://dx.doi.org/10.1038/ejcn.2013.110

24. Livingstone KM, McNaughton SA. Diet quality is associated with obesity and hypertension in Australian adults: a cross sectional study. BMC PUBLIC HEALTH 2016, 16(1):1037. http://dx.doi.org/10.1186/s12889-016-3714-5

25. Wang X, Liu A, Du M, Wu J, Wang W, Qian Y, Zheng H, Liu D, Nan X, Jia L et al. Diet quality is associated with reduced risk of hypertension among Inner Mongolia adults in northern China. PUBLIC HEALTH NUTR 2019:1-12. http://dx.doi.org/10.1017/S136898001900301X

26. Li YC, Jiang B, Zhang M, Huang ZJ, Deng Q, Zhou MG, Zhao ZP, Wang YF, Wang LM. Vegetable and Fruit Consumption among Chinese Adults and Associated Factors: A Nationally Representative Study of 170,847 Adults. BIOMED ENVIRON SCI 2017, 30(12):863-874. http://dx.doi.org/10.3967/bes2017.117

27. Ouyang Y, Zhang B, Wang Z, Su C, Zhang J, Du W, Jiang H, Huang F, Jia X, Wang Y et al. Intake of vegetables and fruits among the Chinese aged 60 and above in 15 provinces (autonomous region and municipatily) in 2015. Journal of Hygiene Research 2019, 48(01):23-27

28. Zhang Q, Chen X, Liu Z, Varma DS, Wan R, Zhao S. Diet diversity and nutritional status among adults in southwest China. PLOS ONE 2017, 12(2):e172406. http://dx.doi.org/10.1371/journal.pone.0172406

29. Fabbri ADT, Crosby GA. A review of the impact of preparation and cooking on the nutritional quality of vegetables and legumes. International Journal of Gastronomy and Food Science 2016, 3:2-11. http://dx.doi.org/10.1016/j.ijgfs.2015.11.001

30. Koiwai K, Takemi Y, Hayashi F, Ogata H, Matsumoto S, Ozawa K, Machado PP, Monteiro CA. Consumption of ultra-processed foods decreases the quality of the overall diet of middle-aged 
Japanese adults. PUBLIC HEALTH NUTR 2019, 22(16):2999-3008.

http://dx.doi.org/10.1017/S1368980019001514

31. Gao X, Xue P, Liu S, Liu H. Current status of dietary knowledge among urban and rural elderly residents in China. Chinese Journal of Gerontology 2012, 32(12):2572-2573. http://dx.doi.org/10. 3969 /j. issn. 1005-9202. 2012. 12. 057

32. He Q. Urban-rural Disparities of Dietary, Nutrition and Health in China: Based on China Health and Nutrition Survey. Huazhong University of Science \& Technology; 2016.

33. Popkin BM, Du S, Zhai F, Zhang B. Cohort Profile: The China Health and Nutrition Survey--monitoring and understanding socio-economic and health change in China, 1989-2011. Int J Epidemiol 2010, 39(6):1435-40. http://dx.doi.org/10.1093/ije/dyp322

\section{Tables}

Table 1. General information.

\begin{tabular}{|c|c|c|c|c|c|}
\hline \multirow[t]{2}{*}{ Variables } & \multirow{2}{*}{$\begin{array}{c}\text { All } \\
\text { participants } \\
(\mathrm{n}=12814)\end{array}$} & \multicolumn{3}{|c|}{ Self-rated health } & \multirow{2}{*}{$p$-value } \\
\hline & & $\begin{array}{c}\text { Poor } \\
(\mathrm{n}=1089 \\
8.5 \%)\end{array}$ & $\begin{array}{c}\text { Moderate } \\
(n=5159 \\
40.3 \%)\end{array}$ & $\begin{array}{c}\text { Good } \\
(n=6566, \\
51.2 \%)\end{array}$ & \\
\hline Age & & & & & $<0.001$ \\
\hline $18-44$ & 3887 (30.3) & $173(4.5)$ & $1323(34.0)$ & $2391(61.5)$ & \\
\hline $45-59$ & $4375(34.1)$ & $307(7.0)$ & $1776(40.6)$ & $2292(52.4)$ & \\
\hline$\geq 60$ & $4552(35.5)$ & $609(13.4)$ & $2060(45.3)$ & $1883(41.4)$ & \\
\hline Gender & & & & & 0.033 \\
\hline Male & $6016(46.9)$ & $472(7.8)$ & $2418(40.2)$ & $3126(52.0)$ & \\
\hline Female & $6798(53.1)$ & $617(9.1)$ & $2741(40.3)$ & $3440(50.6)$ & \\
\hline Marital status & & & & & $<0.001$ \\
\hline Married & $\begin{array}{l}11038 \\
(86.1)\end{array}$ & $868(7.9)$ & $4474(40.5)$ & $5696(51.6)$ & \\
\hline $\begin{array}{l}\text { Others (never married, divorced, widowed, } \\
\text { separated, etc.) }\end{array}$ & 1776 (13.9) & $221(12.4)$ & $685(38.6)$ & $870(49.0)$ & \\
\hline Education level & & & & & $<0.001$ \\
\hline$\leq$ Elementary school & $4132(32.2)$ & $585(14.2)$ & $1917(46.4)$ & $1630(39.4)$ & \\
\hline Middle school & 4068 (31.7) & $286(7.0)$ & $1723(42.4)$ & $2059(50.6)$ & \\
\hline High school & $2845(22.2)$ & $148(5.2)$ & $1024(36.0)$ & $1673(58.8)$ & \\
\hline$\geq$ College & 1769 (13.8) & $70(4.0)$ & $495(28.0)$ & $1204(68.1)$ & \\
\hline Work status & & & & & $<0.001$ \\
\hline Yes & $5891(46.0)$ & $810(11.7)$ & $2965(42.8)$ & $3148(45.5)$ & \\
\hline No & $6923(54.0)$ & $279(4.7)$ & $2194(37.2)$ & $3418(58.0)$ & \\
\hline Place of residence & & & & & $<0.001$ \\
\hline Urban & 5061 (39.5) & $404(8.0)$ & $1925(38.0)$ & $2732(54.0)$ & \\
\hline Rural & $7753(60.5)$ & $685(8.8)$ & $3234(41.7)$ & 3834 (49.5) & \\
\hline
\end{tabular}

Table 2. Diet-related KABs among urban and rural adults. 


\begin{tabular}{|c|c|c|c|c|c|}
\hline Variables & $\begin{array}{l}\text { All participants } \\
(\mathrm{n}=12814)\end{array}$ & $\begin{array}{c}\text { Urban } \\
(\mathrm{n}=5061)\end{array}$ & $\begin{array}{c}\text { Rural } \\
(\mathrm{n}=7753)\end{array}$ & $\mathrm{c}^{2}$ & $p$-value \\
\hline \multicolumn{6}{|l|}{ Diet-related knowledge } \\
\hline Chinese diet Pagoda/DGCR & $3468(27.1)$ & $1955(38.6)$ & $1513(19.5)$ & 566.73 & $<0.001$ \\
\hline Diet knowledge literacy & $4390(34.3)$ & $1896(37.5)$ & $2494(32.2)$ & 8.12 & $<0.001$ \\
\hline \multicolumn{6}{|l|}{ Diet-related attitude } \\
\hline $\begin{array}{l}\text { Healthy diet } \\
\text { Diet-related behaviors }\end{array}$ & 3109 (24.3) & $1313(25.9)$ & $1796(23.2)$ & 12.86 & $<0.001$ \\
\hline Look for nutrition knowledge & $3539(27.6)$ & $2048(40.5)$ & $1491(19.2)$ & 690.72 & $<0.001$ \\
\hline Fruits \& vegetables & $8444(65.9)$ & $3484(68.8)$ & $4960(64.0)$ & 32.25 & $<0.001$ \\
\hline
\end{tabular}

DGCR: Dietary Guidelines for Chinese Residents

Table 3. Awareness proportion of 17 items regarding dietary knowledge. 


\begin{tabular}{|c|c|c|c|c|c|c|c|c|c|}
\hline \multirow[t]{2}{*}{ Items } & \multirow[t]{2}{*}{ Question } & \multicolumn{2}{|c|}{$\begin{array}{c}\text { Total } \\
(\mathrm{n}=12814)\end{array}$} & \multicolumn{2}{|c|}{$\begin{array}{c}\text { Urban } \\
(\mathrm{n}=5061)\end{array}$} & \multicolumn{2}{|c|}{$\begin{array}{c}\text { Rural } \\
(\mathrm{n}=7753)\end{array}$} & \multirow[t]{2}{*}{$c^{2} / t$} & \multirow[t]{2}{*}{$p$-value } \\
\hline & & $\mathrm{n}$ & $\%$ & $\mathrm{n}$ & $\%$ & $\mathrm{n}$ & $\%$ & & \\
\hline Q1 & $\begin{array}{l}\text { Choosing a diet with a lot of fresh } \\
\text { fruits and vegetables is good for one's } \\
\text { health. }\end{array}$ & 9715 & 75.8 & 4036 & 79.7 & 5679 & 73.2 & 70.52 & $<0.001$ \\
\hline Q2* & $\begin{array}{l}\text { Eating a lot of sugar is good for one's } \\
\text { health. }\end{array}$ & 9325 & 72.8 & 3953 & 78.1 & 5372 & 69.3 & 120.16 & $<0.001$ \\
\hline Q3 & $\begin{array}{l}\text { Eating a variety of foods is good for } \\
\text { one's health. }\end{array}$ & 9647 & 75.3 & 3989 & 78.8 & 5658 & 73.0 & 56.13 & $<0.001$ \\
\hline Q4* & $\begin{array}{l}\text { Choosing a diet high in fat is good for } \\
\text { one's health. }\end{array}$ & 9239 & 72.1 & 3933 & 77.7 & 5306 & 68.4 & 130.92 & $<0.001$ \\
\hline Q5 & $\begin{array}{l}\text { Choosing a diet with a lot of staple } \\
\text { foods [rice and rice products and } \\
\text { wheat and wheat products] is not good } \\
\text { for one's health. }\end{array}$ & 5283 & 41.2 & 2156 & 42.6 & 3127 & 40.3 & 6.50 & 0.011 \\
\hline Q6* & $\begin{array}{l}\text { Consuming a lot of animal products } \\
\text { daily (fish, poultry, eggs and lean } \\
\text { meat) is good for one's health. }\end{array}$ & 7965 & 62.2 & 3310 & 65.4 & 4655 & 60.0 & 37.41 & $<0.001$ \\
\hline Q7 & $\begin{array}{l}\text { Reducing the amount of fatty meat and } \\
\text { animal fat in the diet is good for one's } \\
\text { health. }\end{array}$ & 8894 & 69.4 & 3682 & 72.8 & 5212 & 67.2 & 44.05 & $<0.001$ \\
\hline Q8 & $\begin{array}{l}\text { Consuming milk and dairy products is } \\
\text { good for one's health. }\end{array}$ & 10499 & 81.9 & 4241 & 83.8 & 6258 & 80.7 & 19.63 & $<0.001$ \\
\hline Q9 & $\begin{array}{l}\text { Consuming beans and bean products } \\
\text { is good for one's health. }\end{array}$ & 10658 & 83.2 & 4213 & 83.2 & 6445 & 83.1 & 0.03 & 0.865 \\
\hline Q10 & $\begin{array}{l}\text { Physical activities are good for one's } \\
\text { health. }\end{array}$ & 9911 & 77.3 & 4006 & 79.2 & 5905 & 76.2 & 15.63 & $<0.001$ \\
\hline Q11 & $\begin{array}{l}\text { Sweaty sports or other intense } \\
\text { physical activities are not good for } \\
\text { one's health. }\end{array}$ & 5717 & 44.6 & 2400 & 47.4 & 3317 & 42.8 & 26.66 & $<0.001$ \\
\hline Q12* & $\begin{array}{l}\text { The heavier one's body is, the } \\
\text { healthier he or she is. }\end{array}$ & 9767 & 76.2 & 4042 & 79.9 & 5725 & 73.8 & 61.29 & $<0.001$ \\
\hline Q13 & $\begin{array}{l}\text { Eating salty foods can cause } \\
\text { hypertension. }\end{array}$ & 8888 & 69.4 & 3784 & 74.8 & 5104 & 65.8 & 115.04 & $<0.001$ \\
\hline Q14* & $\begin{array}{l}\text { Refined grains (rice and wheat flour) } \\
\text { contain more vitamins and minerals } \\
\text { than unrefined grains. }\end{array}$ & 3595 & 28.1 & 1343 & 26.5 & 2252 & 29.0 & 9.56 & 0.002 \\
\hline Q15* & Lard is healthier than vegetable oils. & 7432 & 58.0 & 3131 & 61.9 & 4301 & 55.5 & 51.33 & $<0.001$ \\
\hline Q16* & $\begin{array}{l}\text { Vegetables contain more starch than } \\
\text { staple foods (rice or wheat flour). }\end{array}$ & 5700 & 44.5 & 2579 & 51.0 & 3121 & 40.3 & 142.04 & $<0.001$ \\
\hline Q17 & $\begin{array}{l}\text { Eggs and milk are the important } \\
\text { sources of high-quality protein. }\end{array}$ & 9036 & 70.5 & 3704 & 73.2 & 5332 & 68.8 & 28.69 & $<0.001$ \\
\hline \multicolumn{2}{|c|}{ All awareness } & 143 & 1.1 & 54 & 1.1 & 89 & 1.1 & 0.18 & 0.670 \\
\hline
\end{tabular}

*negative item

Table 4. Logistic regression analysis predicting the association between diet-related KABs and self-rated health. 


\begin{tabular}{lcccc}
\hline Variables & Poor & Moderate & Good & OR $\left(95 \%\right.$ CI ${ }^{\text {a }}$ \\
\hline Diet-related knowledge & & & & \\
Chinese diet pagoda/DGCR & $176(16.2)$ & $1122(21.7)$ & $2170(33.0)$ & $1.11(1.08,1.15)^{*}$ \\
$\begin{array}{l}\text { Diet knowledge literacy } \\
\text { Diet-related attitude }\end{array}$ & $256(23.5)$ & $1514(29.3)$ & $2620(39.9)$ & $1.12(1.10,1.15)^{*}$ \\
$\begin{array}{l}\text { Healthy diet } \\
\text { Diet-related behaviors }\end{array}$ & $941(86.4)$ & $4761(92.3)$ & $6180(94.1)$ & $1.14(1.09,1.19)^{*}$ \\
Look for nutrition knowledge & $180(16.5)$ & $1153(22.3)$ & $2206(33.6)$ & $1.11(1.08,1.15)^{*}$ \\
Fruits \& vegetables & $649(59.6)$ & $3174(61.5)$ & $4621(70.4)$ & $1.09(1.07,1.12)^{*}$ \\
\hline
\end{tabular}

${ }^{\mathrm{a} O R}$ adjusted for age, gender, marital status, education level, work status, and place of residence.

DGCR: Dietary Guidelines for Chinese Residents; OR: odds ratio; CI: confidence interval;

$* p$-value $<0.01$ 